\title{
HUMANIZAÇÃO DA ASSISTÊNCIA DE ENFERMAGEM EM CENTRO CIRÚRGICO
}

HUMANIZATION OF THE NURSING ASSISTANCE IN THE SURGICAL UNIT

HUMANIZACIÓN DE LA ASISTENCIA DE ENFERMERIA EN UN CENTRO QUIRÚRGICO

\section{Eliana Bedin ${ }^{1}$ \\ Luciana Barcelos Miranda Ribeiro² Regiane Ap. Santos Soares Barreto ${ }^{3}$}

RESUMO: O estudo teve como objetivo levantar as principais literaturas nacionais que abordem a humanização em centro cirúrgico, identificando sua necessidade e importância na atividade da enfermagem. Ao buscar os artigos selecionou-se palavras-chaves e delimitou-se período de 1985-2002, resultando 31 artigos. Após analise, descreveu-se aspectos da formação acadêmica voltada para humanização, considerações éticas à assistência e a necessidade de humanizar o cuidado frente aos avanços tecnológicos. Concluiu-se que humanizar a assistência de enfermagem em centro cirúrgico é um desafio, entretanto, possível e essencial na prática da enfermagem, essencialmente nesta área.

PALAVRAS-CHAVES: Enfermagem de Centro Cirúrgico; Assistência; Ética.

ABSTRACT: This study consisted in a bibliographic review, which goal was a survey of the main national literature that approaches the humanization in the surgical unit, identifying and demonstrating the needs and the importance of the nursing staff daily activities. The search was made selecting the key words and the period between 1985 and 2002, where 31 articles were selected. Analyzing them we discussed about the theme, classifying it in four stages that made sense to the humanization for the nursing assistance in the surgical unit, describing aspects of the nursing graduation releasing for humanization, making ethics considerations to the assistance and demonstrating the needs of the humanized care in the presence of the technological development. We concluded that the humanization of the nursing assistance in the surgical units is a challenge, however, the humanized care is possible and essential to the nursing practice, mainly in a technological environment like the surgical unit.

KEYWORDS: Operating Room Nursing; Assistance; Ethics.

RESUMEN: El estudio tuvo como objetivo levantar las principales literaturas nacionales que aborden la humanización en un centro quirúrgico, identificando su necesidad e importancia en la actividad de la enfermería. Al buscar los artículos se seleccionó palabras-claves y se delimitó el periodo de 1985-2002, resultando 31 artículos. Despues del análisis, se describió aspectos de la formación académica orientada para la humanización, consideraciones éticas a la asistencia y la necesidad de humanizar el cuidado frente a los avances tecnológicos. Se concluye que humanizar la asistencia de enfermería en un centro quirúrgico es un desafio, mas, posible y esencial en la práctica de la enfermería.

PALABRAS CLAVES: Enfermería en Sala Quirúrgica; Etica.

\section{INTRODUÇÃO}

A enfermagem é uma profissão que se desenvolveu através dos séculos, mantendo uma estreita relação com a história da civilização. Neste contexto, tem um papel preponderante por ser uma profissão que busca promover o bem estar do ser humano, considerando sua liberdade, unicidade e dignidade, atuando na promoção da saúde, prevenção de enfermidades, no transcurso de doenças e agravos, nas incapacidades e no processo de morrer.

\footnotetext{
${ }^{1}$ Acadêmica de Enfermagem da Universidade Católica de Goiás - UCG. E-mail: bebedin@bol.com.br End.: Rua Nossa Senhora D’Abadia Qd.:05, Lt.:16, C-01, Jd. Primavera, Trindade-GO, CEP 75380-000 Fone: (62) 96033602

${ }^{2}$ Acadêmica de Enfermagem da Universidade Católica de Goiás - UCG. E-mail: luanjim@ig.com.br End.: Rua oito, nº 215 Bairro Santuario, Trindade-GO, CEP.: 75380-000 Fone: (62) 5051394

${ }_{3}^{3}$ Professora assistente da Faculdade de Enfermagem da Universidade Federal de Goiás - UFG. E-mail: rimarina@uol.com.br.
} 
Com o avanço científico, tecnológico e a modernização de procedimentos, vinculados à necessidade de se estabelecer controle, o enfermeiro passou a assumir cada vez mais encargos administrativos, afastando-se gradualmente do cuidado ao paciente, surgindo com isso a necessidade de resgatar os valores humanísticos da assistência de enfermagem. Para ZEN \& BRUTSHER (1986, p.06):

"não se pode ficar atrás ou as margens desse processo. É dever de todos acompanhar o desenvolvimento das ciências humanas, científicas, culturais e tecnológicas dos tempos atuais o que vem implicar não só na necessidade da aquisição de novos conhecimentos como também na atualização dos mesmos."

WALDOW (1998, p.62), salienta a importância de conciliar e harmonizar as diversas funções do enfermeiro, quando afirma:

"o cuidado humanístico não é rejeição aos aspectos técnicos, tão pouco aos aspectos científicos, o que se pretende ao revelar o cuidado é enfatizar a característica do processo interativo e de fruição de energia criativa, emocional e intuitiva, que compõe o lado artístico além do aspecto moral."

$\mathrm{Na}$ amplitude de sua assistência, a enfermagem, assim como as demais profissões de saúde, se subdividem em várias áreas, neste momento, voltamos nossa atenção à humanização da assistência de enfermagem em centro cirúrgico.

Segundo FIGUEIREDO (2002, p.256),

"os profissionais de enfermagem que atuam no centro cirúrgico são geralmente os responsáveis pela recepção do cliente na sua respectiva unidade, (que deve ser) personalizada, respeitando sempre suas individualidades; o profissional deve ser cortês, educado e compreensivo, buscando entender e considerar as condições do cliente que normalmente já se encontra sob efeito dos medicamentos pré-anestésicos."

As atividades de enfermagem no centro cirúrgico, muitas vezes, podem ser limitadas a segurar a mão do paciente na indução anestésica, ouví-lo, confortá-lo e posicioná-lo na mesa cirúrgica.

A importância e a responsabilidade da enfermeira quanto à observação e atendimento das necessidades psicossomáticas do paciente cirúrgico deve ser detectada, uma vez que possui função específica na eficácia da terapêutica de seus pacientes, pois dependendo de sua atitude pode facilitar ou impedir um programa de recuperação, visto que este paciente é invadido por medo do desconhecido num ambiente estranho (ZEN \& BRUTSHER, 1986).

Até alguns anos atrás a função do enfermeiro na unidade de centro cirúrgico era dirigida para os aspectos gerenciais, o que o afastava do contato com o paciente, mas com algumas modificações na sistematização da assistência, o enfermeiro de centro cirúrgico sentiu a necessidade de prestar assistência mais direta ao paciente em todas as etapas do processo cirúrgico, destacando a importância desta para $O$ sucesso do tratamento $e \quad O$ pronto restabelecimento do paciente (MEE KER \& ROTHROCK, 1997).

Para OLIVEIRA (2001, p.104),

"humanizar, caracteriza-se em colocar a cabeça e o coração na tarefa a ser desenvolvida, entregar-se de maneira sincera e leal ao outro e saber ouvir com ciência e paciência as palavras e os silêncios. $O$ relacionamento e o contato direto fazem crescer, e é neste momento de troca, que humanizo, porque assim posso me reconhecer e me identificar como gente, como ser humano."

Ainda VILA \& ROSSI (2002, p.17) referem que a "humanização deve fazer parte da filosofia de enfermagem. O ambiente físico, os recursos materiais e tecnológicos não são mais significativos do que a essência humana. Esta sim irá conduzir o pensamento e as ações da equipe de enfermagem, principalmente do enfermeiro, tornando-o capaz de criticar e construir uma realidade mais humana (...)".

Não é apenas uma questão de mudança do espaço físico, mas principalmente uma mudança nas ações e comportamento dos profissionais frente ao paciente e seus familiares.

Em meio a tantas afirmações positivas, foi grande nossa decepção no primeiro contato com a unidade de centro cirúrgico, com o distanciamento entre teoria e prática, onde o enfermeiro era visto como "o administrador", ocupando-se da manutenção de equipamentos, mesas, bandejas, papéis, entre outras rotinas e o paciente permanecia invisível a todos, sendo tratado como um objeto e não como um corpo vivo.

Este distanciamento aliado ao fato de que há escassez de literatura que envolva a humanização em centro cirúrgico, levou-nos à realização de um estudo que contemplasse a formação acadêmica relacionada à humanização, as considerações éticas envolvidas na assistência (des)humanizada, a necessidade de humanizar o cuidado frente aos avanços tecnológicos e a possibilidade de humanizar o cuidado no centro cirúrgico.

\section{MATERIAL E MÉTODOS}

O presente trata-se de um estudo qualitativo, realizado através de revisões bibliográficas, nos bancos de dados: Lilacs, Scielo, BDENF, no período de 1985 a 2002, por meio das palavras-chave: cliente cirúrgico, tratamento humanizado, assistência humanizada, centro cirúrgico, cuidados na admissão em centro cirúrgico e cuidar em enfermagem. Durante a pesquisa foram encontrados 1100 artigos, dentre os quais, utilizados 31 , após a análise do título e resumo dos mesmos quanto à adequação ao tema proposto. 


\section{A FORMAÇÃO DO ENFERMEIRO PARA O CUIDADO HUMANIZADO}

Com relação à formação do aluno de graduação, o tema "comunicação", sua importância para o estabelecimento de um diálogo franco $e$ esclarecedor com o cliente, suas funções e formas, a comunicação terapêutica e sua aplicabilidade no cotidiano das ações de enfermagem, são debatidas constantemente com os graduandos, e mesmo com o empenho de docentes e discentes, durante o processo de ensino-apendizagem, mais especificamente nas atividades práticas, deparam com situações em que o processo de comunicação com o cliente parece ineficaz e/ou não oferece subsídios para o planejamento da assistência (AZEVEDO, 2002, p.19).

As atividades educativas dos profissionais de enfermagem vêm sendo discutidas em vários momentos pelas entidades representativas. Almeida et al apud ZAGO \& CASAGRANDE (1996, p.54), salientam que,

"a educação em saúde precisa ser melhor estudada para que o enfermeiro possa recriar o processo educativo, contendo conhecimentos de pedagogia, porém transformado, para que não seja uma simples transferência de informações aos indivíduos, mas, um ensino que busca um resultado mais imediato sobre o modo como eles cuidam de sua saúde, porque se fundamenta uma necessidade imediata."

Durante o processo de formação os alunos são colocados em situações onde se torna necessário o processo de comunicação entre eles e o paciente, utilizando-se tanto da forma verbal, quanto não-verbal. Para AZEVEDO (2002, p.21), "a comunicação franca e aberta auxilia alunos e clientes a enfrentarem momentos de incerteza e ansiedade durante a realização de cuidados."

Por outro lado, ZAGO \& CASAGRANDE (1996, p.57), lembram que,

"os enfermeiros cirúrgicos brasileiros valorizam e desenvolvem atividades educativas com o paciente. Mas, a extensão, a visão desses profissionais quanto à atividade, o contexto cultural em que ocorrem e os padrões culturais dessa atividade ainda são incompatíveis com os pressupostos de educação e ensino de pacientes e de auto cuidado."

Ao analisarmos vários artigos observamos que o avanço das ciências tem contribuído para as especializações que, em certos momentos foge ao que entendemos como assistência ao ser humano, mas SANTOS et al (2002, p.28), afirmam que "só uma equipe de enfermagem humanizada é que poderá humanizar o paciente". Já para AZEVEDO (2002, p.23) a "comunicação é uma parte do cuidar adquirido pelos profissionais em forma de competência interpessoal".

No centro cirúrgico, um dos fatores que vem afastando os profissionais de suas atividades é o avanço tecnológico desta unidade, o que tem favorecido a complexibilidade dos procedimentos ali realizados. Avelar apud JOUCLAS et al (1998, p.44) coloca que,

"(...) o enfermeiro de centro cirúrgico enfrenta uma crise compreendida pelo desafio entre a racionalidade cientifica do modelo biológico de assistência à saúde e seus valores culturais, sociais e éticos. Assim em seu dia-a-dia, vêse constantemente impulsionado a transferir e adiar suas escolhas e ideais profissionais, entre as decisões tecnocratas, sentindo-se, cada vez mais, como um instrumento de controle, o que vem pesando sobre si como uma grande e constante ameaça."

Amparados nestas afirmações asseguramos que não é possível termos profissionais conscientizados da necessidade de prestarem assistência humanizada aos pacientes se não forem preparados na graduação para estarem desempenhando tal atividade. AZEVEDO (2002, p.19), afirma que, "tanto para os alunos quanto para os enfermeiros a dificuldade no relacionamento enfermeiro/paciente é uma realidade enfrentada diariamente".

A que se considerar comum certa dificuldade em estabelecer e/ou manter uma comunicação efetiva a clientes com nível de consciência alterado ou aqueles mais "reinvidicadores", como concluiu (AZEVEDO, 2002, p.23). Entretanto, ainda concordamos com VILA \& ROSSI (2002, p.147) quando revelam que "se cada um de nós entender e aceitar quem somos e o que fazemos, seremos capazes de lutar e agir para que essa mudança aconteça." As bases da humanização são as ações do enfermeiro frente ao paciente, priorizando atitudes de respeito e privacidade, atingindo a satisfação do cliente. Concordamos com OLIVEIRA et al (2002, p.03) quando ressaltam que, "esta humanização deve ser implantada no coração antes mesmo de ser implantada no trabalho".

\section{CONSIDERAÇÕES ÉTICAS NA ASSISTÊNCIA (DES) HUMANIZADA NO CENTRO CIRÚRGICO}

Levando em conta a ética profissional da enfermagem, a esses profissionais não compete apenas as ações técnicas e especializadas, mas a atenção às pessoas doentes da melhor maneira possível respeitando sua individualidade (GUIDO, 1995, p.103). Ainda, de acordo com a DECLARAÇÃO UNIVERSAL DOS DIREITOS HUMANOS (2003), Art. $1^{\circ}$ "todos os seres humanos nascem livres e iguais em dignidade e em direitos. Dotados de razão e de consciência, devem agir uns para com os outros em espírito de fraternidade", não sendo necessário ações individualizadas, mas sim, ações coletivas que tenham como objetivo promover o bem estar do outro.

O Código de Ética dos profissionais de enfermagem, por meio da Resolução n. ${ }^{\circ} 240 / 2000$, p.35, capítulo I (COFEN, 2000), estabelece que,

"o profissional da enfermagem respeita a vida a dignidade e os direitos da pessoa humana, em todo seu ciclo vital, a discriminação de qualquer natureza, assegura ao cliente uma assistência 
de enfermagem livre de danos decorrentes de imperícia, negligência ou imprudência, cumpre e faz cumprir os preceitos éticos e legais da profissão, exercendo a enfermagem com justiça, competência, responsabilidade e honestidade."

Ao descrevermos as atividades desenvolvidas pela enfermagem no centro cirúrgico, temos: recepção e identificação do paciente, encaminhamento à sala de cirurgia, preparação e montagem da sala, teste e verificação da segurança dos equipamentos, mobilização e transporte de pacientes, recepção e avaliação em sala de recuperação anestésica, assistência individualizada e humanizada, encaminhamento e alta com segurança e respeito (GUIDO, 1995).

Consideramos que a humanização deve permear cada uma destas atividades, mesmo que equipamentos estejam presentes no procedimento. No centro cirúrgico, há momentos em que o paciente é esquecido em detrimento de questões burocráticas, ambientais, e até por falta de respeito. Durante a fase pré-anestésica, o paciente "pode ficar" exposto e até mesmo nu sobre a mesa cirúrgica aguardando o efeito dos anestésicos.

Brandão apud JOUCLAS et al (1998, p.46), demonstra claramente, quando coloca a visão do paciente cirúrgico:

"a caminho do centro cirúrgico, a maca atravessa corredores gelados, porém o frio dentro de mim não tem a ver com a temperatura do dia. Entre o apartamento e a mesa de operação é um longo caminho. Luto contra cada instante, tenho que chegar intacto à mesa. Preciso vencer alguns metros de corredores. Conto a possibilidade de vida por metros. Não há dor, indisposição, náuseas, eu poderia ter caminhado, batendo um papo (...)".

No trabalho diário de um centro cirúrgico é de responsabilidade da enfermeira a recepção do paciente que na maioria das vezes é feita de forma mecânica junto a uma identificação que passa de nome e sobrenome para número e patologia. Ao realizar um estudo sobre a humanização da assistência de enfermagem prestada no centro cirúrgico, RODRIGUES (2000, p.18), traz fragmentos de entrevistas que demonstram o tratamento ético que é dispensado aos pacientes sob a ótica dos mesmos,

"quando me chamaram pelo meu nome, tive a certeza que sabiam o que estavam fazendo, isso me deixou mais tranqüila",

"fui recebida com bom dia, mas depois me deixaram sozinha em uma sala e eu só ouvia conversas no corredor, senti medo, foi muito ruim, eu estava angustiada e as moças ficaram discutindo preço de celular".

"O paciente tem direito a ser identificado pelo nome e sobrenome. Não deve ser chamado pelo nome da doença ou do agravo à saúde, ou ainda de forma genérica ou quaisquer outras formas impróprias, desrespeitosas ou preconceituosas" (SÃO PAULO, 1999, html).
O paciente é levado até a sala de cirurgia de forma fria, sem se estabelecer um diálogo ou mesmo uma relação de confiança profissional-paciente; depois de colocado na mesa operatória é esquecido, e a enfermagem passa a assumir função tecnicista, dispensando atenção aos equipamentos e seu funcionamento adequado, sem maiores esclarecimentos ou respostas às suas angustias. De acordo com o documento acima citado,

"o paciente tem direito a informações claras, simples e compreensivas, adaptadas à sua condição cultural, sobre as ações diagnosticadas e terapêutica, o que pode decorrer delas, a duração do tratamento, a localização de sua patologia, se existir necessidade de anestesia, qual o instrumental a ser utilizado e quais órgãos do corpo serão afetados pelo procedimento."

Quando se encerra o ato cirúrgico o paciente é transferido da sala de cirurgia para a sala de recuperação pós-anestésica, e neste momento, conforme a condição hemodinâmica, ou seja, dependendo do sucesso do ato anestésico-cirúrgico, o paciente acaba por não receber a atenção que a ele deveria ser dedicada, independente de seu estado geral.

Castellanos et al. apud GUEDES et al (2001, p.22) ressaltam que,

"o enfermeiro é o responsável pelo cuidado do paciente do centro cirúrgico e, se ele não o coloca em primeiro plano, irá atender à cirurgia e não ao paciente, promovendo, assim o controle de material, equipamentos e pessoal voltado para a cirurgia, tornando o paciente um objeto de trabalho, mas não o ser principal, sujeito desencadeante do processo."

A atenção, muitas vezes, fica restrita a simples expressões como: "está tudo bem", "respira fundo" ou "calma" sem ao menos olhar diretamente para ele. Relato de médicos que passaram para a situação de paciente demonstram essa, como Rabin \& Rabin apud CAPRARA \& FRANCO (1999, p.652) colocam ,

"fiquei desiludido com a maneira impessoal de se comunicar com os pacientes. Não demonstrou em momento nenhum, interesse por mim como pessoa que está sofrendo. Não me fez nenhuma pergunta sobre meu trabalho. Não me aconselhando a respeito do que tinha que fazer ou do que considerava importante psicologicamente, para o enfrentamento das minhas reações, a fim de me adaptar e responder a doença degenerativa. Ele como médico experiente da área, mostrou-se atencioso, preocupado, somente no momento em que me apresentou a curva de mortalidade da esclerose amiotrófica."

Fato que merece destaque e muitas vezes é desencadeado por problemas administrativos, é o cancelamento de cirurgias, que já causou angústia e insegurança considerável ao paciente, prejudicando-o e desrespeitando-o, pois geralmente só é informado no centro cirúrgico, sendo que cada paciente tem sua 
reação e resposta particular, (ANTONIO et al, 2002), e para alguns pode ter efeitos desastrosos, mesmo que sejam esclarecidos ou que estes tentem racionalizar e compreender a situação (ANTÔNIO et al, 2002).

Baseados no Código de Ética dos profissionais de enfermagem (COFEN, 2000, p.34), verificamos no capitulo III, artigo $16^{\circ}$ que é de responsabilidade da nossa profissão "assegurar ao cliente uma assistência de enfermagem livre de danos decorrentes de imperícia, negligência ou imprudência".

Associado ao cancelamento de cirurgias outros "dilemas éticos" podem ser relatados no atendimento ao cliente na eminência de uma cirurgia, como a invasão de sua privacidade e o desrespeito dentro da sala operatória; não se pode ignorar que a enfermagem no cuidado diário, toca e expõe o paciente muitas vezes sem autorização, adotando posturas de poder sobre o mesmo. Sentimentos de constrangimento, vergonha e embaraço, são demonstrados, porém o paciente pouco questiona acreditando ser imprescindível a invasão para sua recuperação. Entretanto, o sujeito do processo de trabalho da enfermagem, é um ser humano com personalidade, dignidade, preconceito e pudor (PUPULIM \& SAWADA, 2002). Por outro lado, GUIDO (1995, p.106) ainda nos mostra claramente esses dilemas quando cita algumas situações a serem corrigidas para que se alcance a humanização e o respeito que é de direito do paciente:

"falta de atenção para com o cliente no que se refere a sua privacidade, além de comentários e discussões inoportunas e de falta de registro de situações e ocasiões importantes para o ensino $e$ a pesquisa, no entanto sem autorização ou mesmo justificativa para 0 cliente daquele ato ou conduta."

Lembrando novamente o Código de Ética da Enfermagem citamos os artigos 27 e 28 do capítulo IV que tratam dos deveres do profissional enfermeiro, sendo, o "Art. 27-Respeitar e reconhecer o direito do cliente de decidir sobre sua pessoa, seu tratamento e seu bem estar" e o "Art.28-Respeitar o natural pudor, a privacidade e a intimidade do cliente" (COFEN, 2000).

Ao discorrer sobre direitos e deveres, GUIDO (1995, p.106) lembra que,

"(...) todas as pessoas que convivem em busca de uma melhor condição de vida, querem seus direitos, esquecendo, às vezes, os deveres. A liberdade da equipe multiprofissional pode tolher a do cliente, ameaçando sua estrutura emocional, no entanto, não podemos esquecer que os profissionais de saúde também tem sentimentos e muitas vezes preocupam-se em agir com ética, buscando solucionar ou minimizar o sofrimento da maneira menos agressiva possível."

Ao se respeitar e atender as necessidades e direitos do paciente, a equipe que com ele se relaciona terá sucesso em seu trabalho, já que é de responsabilidade principalmente do enfermeiro fazer com que esses direitos sejam cumpridos. Salientam
MENDES et al (2000, p.217) a respeito do profissional enfermeiro:

"(...) mais do que qualquer outro profissional de saúde, os enfermeiros tem freqüentemente tempo, oportunidade e acima de tudo preparo para demonstrar seu conhecimento pelo direito do paciente, ser assistido com dignidade e ainda mais, de promover estes direitos, através de suas ações."

Com isso é possível observar que, o atendimento dedicado ao paciente se distancia demasiadamente da teoria já que na prática em várias situações, a atenção individualizada é praticada de forma mecânica. Assim, a ética profissional que tanto deve ser conservada acaba sendo substituída por práticas adotadas devido à escassez de tempo ou mesmo por comodidade de certos profissionais, tornando o ambiente (des) humano.

\section{A HUMANIZAÇÃO FRENTE AO AVANÇO TECNOLÓGICO}

Ao longo da história a enfermagem vem se desenvolvendo, e a partir da Revolução Industrial teve um impulso considerável, em pesquisas, técnicas e novos conceitos que conquistou perante a sociedade; por outro lado, a ciência obteve um grande avanço a partir do momento em que se aliou à tecnologia, beneficiando-se dos princípios científicos e dos equipamentos mais simples aos mais sofisticados (RIBEIRO et al, 1999, p.15).

A tecnologia não consiste exclusivamente na aplicação pura do conhecimento, mas de vários conhecimentos reunidos, com a finalidade de encontrar a solução para uma anormalidade, RODRIGUES (1999, p.61) afirma que, "a descoberta científica resulta da busca do saber pelo saber em si, ainda que se admita que o cientista, sempre tenha um interesse por aquilo que esteja pesquisando".

É claro que a tecnologia é essencial, desejável e necessária à modernização do atendimento aos pacientes no centro cirúrgico, tornando-se útil para prolongar a vida e diminuir o sofrimento de muitas pessoas, no entanto, não se deve deixar o paciente de lado dando prioridade aos aparelhos, conforme descreve RIBEIRO et al (1999, p.19) ao dizer que, "de nada adianta ser um humanista e observar o homem que morre por falta de tecnologia, nem ser rico em tecnologia apenas para observar os homens que vivem e morrem indignamente".

Deve-se buscar o uso da tecnologia humanizada por parte dos profissionais que assistem o paciente no cento cirúrgico entretanto, analisando LOPES et al (1998, p.56) comprovamos que,

"na equipe de saúde este fenômeno não está presente, pois o paciente deixa de ser uma pessoa para ser um caso interessante. 0 paciente individualizado, com seus problemas, temores e necessidades não é sempre levado em conta".

O avanço tecnológico na área da saúde é uma grande conquista, porém, o melhor é associá-lo à 
humanização e a comunicação terapêutica, com intuito de obter resultados mais satisfatórios em relação ao bem estar dos clientes e da ciência.

Analisando a tecnologia e a humanização, observa-se que estas possuem características distintas, mas se faz necessário o uso de ambas para que o resultado do atendimento seja satisfatório por parte dos pacientes. Baseados nestas afirmações percebe-se que a humanização na enfermagem não é possível sem a tecnologia e vice-versa, não se pode aplicar a tecnologia nas ações da enfermagem sem que a humanização esteja presente (CARRARO, 2000, p.43).

Para CARRARO (2000, p.42),

"precisamos despir-nos da idéia que humanização e tecnologia compreendem apenas ações atuais e equipamentos de ultima geração. Não desconsidero estas idéias, apenas quero chamar a atenção para possibilidades de humanizar a aplicação de tecnologias simples, antigas e corriqueiras na enfermagem, lembrando que muitas vezes estão à nossa disposição e não as valorizamos em detrimento da sofisticação."

É importante salientar que o avanço tecnológico na área da saúde é uma grande conquista, mas seria melhor associar esta tecnologia à uma assistência voltada para o paciente, onde o enfermeiro priorize "estar com" o ser humano, preservando-o de infortúnios e singularizando a assistência humanizada, com vistas a obter resultados mais satisfatórios em relação ao bem estar dos pacientes. RODRIGUES (1999, p.19) lembra que, "o tema tecnologia não se refere a algo que está a influenciar a nossa vida, refere-se antes a própria realidade na qual estamos totalmente inseridos e que, portanto, não podemos ignorar".

Ainda VILLA \& ROSSI (2002, p.139) ressaltam que,

"a humanização deve fazer parte da filosofia de enfermagem. $\mathrm{O}$ ambiente físico, os recursos materiais e tecnológicos são importantes, porém não mais significativos do que a essência humana. Esta sim, conduzirá o pensamento e as ações da equipe de enfermagem, principalmente do enfermeiro, tornando-o capaz de criticar e construir uma realidade mais humana, menos agressiva e hostil para os pacientes que diariamente necessitam de atendimento (...)."

A partir dessas reflexões nos é possível afirmar que o avanço tecnológico não afasta o enfermeiro do seu objetivo primordial, de assistir os clientes de forma integral. Para Folta apud RIBEIRO et al (1999, p.19), "não há evidências de que menor atenção à tecnologia implique em maior cuidado direto e humanizado, então, se faz necessário um equilíbrio entre a atenção dispensada, a tecnologia e a humanização do cuidado ao paciente".
Para isso pode-se utilizar meios que favoreçam a interligação, onde um deles é a comunicação, como evidenciam LOPES et al (1998, p.60),

"a importância da comunicação é a explicação mais eficaz sobre os variados procedimentos, pois, além de promover maior grau de conhecimento e esclarecimento, favorece sentimentos de segurança e cooperação".

Nesta perspectiva, muito empenho é necessário para que o progresso da tecnologia e da ciência não acabe por esvaziar a profissão de seu conteúdo humano, sendo imprescindível associar ao exercício profissional, a tecnologia e o conhecimento da personalidade do paciente, mantendo a assistência digna a quem tem sentimentos e racionalidade, e não a um amontoado de sinais, sintomas e reações (ZEN \& BRUTSCHER, 1986, p.06). Enfim, é indispensável a "tecnologia do calor humano" nas relações enfermeiropaciente, característica esta que enobrece, dignifica e eleva os ideais da profissão de enfermagem.

\section{HUMANIZAR O CUIDADO NO CENTRO CIRÚRGICO É POSSÍVEL?}

Fazendo uma retrospectiva sobre a enfermagem, suas origens e evolução até o presente momento, não restam dúvidas que o cuidar é sua principal característica e seu marco referencial, representando as crenças e valores predominantes da prática da enfermagem. Com o passar dos tempos têm surgido várias definições de cuidar/cuidado de acordo com diferentes concepções. WALDOW (1992, p.30) afirma que o "cuidado pode ser considerado como a conotação de atenção, preocupação para, responsabilidade por, observar com atenção, com afeto, amor ou simpatia. Em geral, o termo implica a idéia de fazer, de ação".

Para que o cuidado humano tenha efeito positivo, deve-se incorporar mais de um fator em sua estrutura, como a valorização da humanização, a criatividade na promoção da fé e da esperança, promoção do ensino-aprendizagem entre os profissionais, a prestação de cuidados, a expressão de sentimentos negativos e positivos, entre outros. TANJI \& NOVAKOSKI (2000, p.802), afirmam que "o cuidado é imprescindível em diferentes situações da vida do ser humano, podendo ser adaptadas e ajustadas conforme a necessidade".

A rotina e a complexidade do ambiente fazem com que os membros da equipe de enfermagem, na maioria das vezes, esqueçam de tocar, conversar e ouvir o ser humano que está a sua frente (VILLA \& ROSSI 2002, p.143), conseqüências de uma rotina diária, que exigem um grande esforço físico e psíquico dos profissionais; ao realizar um estudo para avaliar os sintomas físicos de estresse na equipe de enfermagem em um centro cirúrgico. CARVALHO \& LIMA (2001, p.31) chamam a atenção para, "... as muitas queixas que caracterizam sintomas físicos de estresse, dando a impressão de que esses sintomas tem interferido negativamente, tanto na vida do funcionário, quanto no seu trabalho...". 
Amparados nestas afirmações, constatamos que o trabalho do enfermeiro de centro cirúrgico, em determinados momentos constitui-se como um instrumento da equipe cirúrgica, ocupando-se de tarefas administrativas, como afirmam GUEDES et al (2001, p.24), "percebe-se que a função burocrática, planejamento, organização e o controle sejam elementos firmemente incorporados ao seu trabalho diário", não restando tempo do seu expediente para dedicar-se aos cuidados com o paciente.

Desta forma, para que consigamos humanizar o atendimento de enfermagem é preciso que a equipe seja conscientizada e preparada para fazer a diferença no cuidado, passando a entender o paciente de forma humana; o enfermeiro é responsável por orientar, sanar dúvidas pertinentes ao procedimento trazendo uma maior tranqüilidade e segurança, não esquecendo de que ele também necessita de um ambiente adequado para realizar o seu trabalho.

Apoiados em nossas experiências acadêmicas temos observado que a cirurgia em si é um fator de estresse, tanto para o paciente, como para a equipe cirúrgica, no entanto é necessário que os profissionais tenham consciência de que o objetivo de seu trabalho é a recuperação do paciente, preocupando-se em detectar sinais de ansiedade, estresse e/ou outros fatores que possam interferir no bom andamento do ato cirúrgico. Como afirmam SANTOS et al (2002, p.26),

"a importância da qualidade da assistência de enfermagem nesse momento é capaz de contribuir para avaliar a tensão, ao transmitir para o cliente informações que lhe permitam enfrentar a situação em que se encontra com menos temor".

A boa qualidade da assistência de enfermagem ao paciente cirúrgico inicia-se no pré-operatório. Segundo VALLE et al. (1997, p.35) analisando as orientações pré-operatórias sob a ótica dos pacientes, os mesmos "exaltam a importância do preparo préoperatório efetuado pelas enfermeiras do centro cirúrgico trazendo-lhes, orientações acerca do procedimento cirúrgico e transmitindo-lhes segurança".

Ainda D'Assumpção apud CRUZ \& VARELA (2002, p.52) descrevem sobre o medo, a incerteza e a angústia demonstrada pelo paciente ao transcreverem trechos de entrevistas, como este:

"ao me levarem para a sala de cirurgia, por favor não me deixem sozinho e sem qualquer informação sobre o que irá acontecer (...), para mim, tudo é novidade, tudo é assustador. Porém, se alguém que eu já conheça, estiver junto de mim, estarei seguro e me será mais fácil enfrentar tudo aquilo que virá em seguida."

O paciente orientado quanto aos procedimentos a que será submetido no centro cirúrgico é um paciente com níveis de ansiedade, insegurança e medo menores do que aquele sem acesso a qualquer orientação.

Ao chegar no centro cirúrgico é necessário que o enfermeiro acolha calorosamente o paciente, encaminhando-o à sala de cirurgia, no entanto, no dia- a-dia das atividades cirúrgicas, há uma insatisfação por parte dos pacientes, quanto à prontidão ao atender chamados, ao apoio, às orientações recebidas desde a recepção até a sala operatória e durante $\mathrm{o}$ ato cirúrgico, o que leva a inferir que os cuidados de enfermagem no trans-operatório, na maioria das vezes, não estão incorporados ao cotidiano das atividades desenvolvidas, (JOUCLAS et al, 1998, p.47).

Ainda SANTOS et al (2002, p.26) descrevem que, "no centro cirúrgico, o paciente freqüentemente é assistido de forma mecânica, impessoal e seus problemas de natureza psicológica ou mesmo social muitas vezes são ignorados...". Ao estudarem a relação entre pacientes e profissionais quanto à prática da humanização, CAPRARA \& FRANCO (1999, p.651), trazem fragmentos de entrevistas realizadas com pacientes, entre estas se encontra uma que caracteriza a despersonalização a que é submetido o paciente ao ser internado, ao relatar que, "as próprias vestes são substituídas por roupas personalizadas e, como identificação, um simples número". Desta maneira constata-se que mais uma vez o cotidiano se afasta do contexto teórico, podendo ser referida como a falta de sensibilidade da instituição para com o paciente. SILVA et al (2001, p.587) relatam a

"importância do enfermeiro pensar ao dispensar cuidados aos seus seres cuidados, mediados pela preocupação e desvelo pelo outro, considerando este momento de comunhão que se dá entre aquele que, cientificamente e humanamente, aprendeu os meios de ajudar o outro nas suas necessidades de saúde e de doença, e o outro que necessita receber tais cuidados."

$\mathrm{Na}$ atividade diária de um centro cirúrgico encontramos variados comportamentos e atitudes entre os profissionais, sendo mais comuns as que desrespeitam o ser humano, como lembram CRUZ \& VARELA (2002, p.52) sobre

"o abandono do paciente para cumprimentos efusivos e demorados com companheiros(as) de trabalho, o surgimento inoportuno, naquele local e naquele momento, de funcionários, dirigindo-se à enfermeira próxima ao paciente, para informar que: o aspirador desta sala não está funcionando, ou está faltando oxigênio nesta sala, ou o ar condicionado não está funcionando, ou ainda o anestesista não chegou."

Essas situações podem até ser consideradas comuns e naturais entre os profissionais, mas não o são para os pacientes, para esses, estas situações se colocam como ameaçadoras, assustadoras e geradoras de conflitos e ansiedades, desencadeando diferentes sentimentos que podem vir a complicar o desenvolvimento da cirurgia ou do pós-operatório (ANTONIO et al, 2002, p.37).

Ao sair da sala de cirurgia a maioria dos pacientes são encaminhados para a sala de recuperação pós-anestésica, onde o cliente deve ser recebido pelo enfermeiro e ter as suas necessidades 
sanadas. Soares apud TEIXEIRA et al (1994, p.255), afirmam que, "um bom relacionamento entre enfermeiro e paciente reduz o impacto da cirurgia e as possibilidades de complicação, além de promover adaptação mais rápida...”.

A presença do enfermeiro ao lado do paciente, desenvolvendo uma relação de ajuda e compartilhando este momento tão angustiante, Ihe trará conforto e segurança, tornando mais ameno e menos doloroso este momento. Ao avaliar os cuidados de enfermagem na sala de recuperação pósanestésica, obteve-se alto grau de satisfação por parte dos pacientes nos itens: segurança demonstrada pelo pessoal de enfermagem nos cuidados, acolhimento do paciente e apoio, desde a chegada até ser encaminhado a unidade de internação (JOUCLAS et al, 1998, p.47).

No entanto, as orientações recebidas pelo paciente na sala de recuperação pós-anestésica muitas vezes não estão de acordo com o que é preconizado pelos referenciais teóricos, como coloca TEIXEIRA et al (1994, p.254) ao afirmarem que, "prestar informações específicas ao paciente sobre as sensações esperadas, pode ser útil, contudo, é importante antes de fornecer qualquer informação, ouvir o paciente, seus temores e dúvidas ...", evitando que o mesmo fique sem saber o porque dos sintomas que está apresentando e até quando permanecerá neste estado desconfortante.

Após estas reflexões, pode-se afirmar que desde o momento em que o paciente é admitido para a realização de procedimento cirúrgico até a alta hospitalar, este não é mais o único responsável pelo que acontece consigo, mas toda a equipe. Durante sua permanência no centro cirúrgico, a responsabilidade recai sobre a equipe cirúrgica e mais diretamente no enfermeiro, passando a responder por tudo o que está ou possa acontecer com o mesmo, por isso, segundo SANTOS et al (2002, p.26) o enfermeiro de centro cirúrgico deve

"livrar-se de seu papel puramente técnico e integrar-se no cuidado total daquele cliente que está a sua frente. Em tão poucas ocasiões o indivíduo está tão dependente de outra pessoa com relação a sua segurança e bem estar quanto no período pré, trans e pós-operatório, ocasião em que precisa integrar-se ao desconhecido (ambiente e pessoas)."

Assim, é necessário que o enfermeiro esteja atento a todas as reações apresentadas pelo paciente nestes períodos, sendo imprescindível, segundo JOUCLAS et al (1998, p.48) "a utilização de um processo de interação interpessoal que ultrapasse 0 fazer mecânico, promovendo o espírito de humanização dos cuidados". Neste sentido, é inevitável motivar e conscientizar os profissionais para as mudanças indispensáveis na obtenção de um ambiente mais humanizado no centro cirúrgico. RODRIGUES (2000, p.20) lembra que,

"humanizar o atendimento de

enfermagem em centro cirúrgico tem sido um desafio constante, pois encontramos resistência de alguns funcionários e de vários profissionais de outras áreas, porém, acreditamos que o cuidado humanizado é essencial para a prática da enfermagem."

\section{CONSIDERAÇÕES FINAIS}

Diante do exposto sobre humanização no período transoperatório e os vários fatores que interferem nesta, podemos afirmar que não teremos uma equipe humana, em suas atividades diárias, se não for preparada para tal em sua formação. Com isso, fica um questionamento, que muito tem nos incomodado. Como podemos falar em humanização do paciente, se antes não podemos constatar a presença de equipes humanizadas?

Surge a necessidade de se repensar e reavaliar os conteúdos que estão sendo ministrados durante a graduação, quanto à qualidade do ensino e dos profissionais que estão sendo formados e encaminhados para o campo de trabalho, sendo imprescindível que os graduandos recebam uma formação mais humanista.

As ações éticas contempladas na graduação devem ser praticadas pelos enfermeiros ao assistirem seus pacientes, entretanto, a repetição diária das atividades, fazendo o profissional agir de forma mecânica, a sobrecarga de trabalho e até mesmo o comodismo, tem afastado consideravelmente a prática da teoria, deixando com isso indícios de insatisfação dos clientes com relação aos cuidados recebidos.

Aliado a estes fatores, encontramos os avanços tecnológicos interferindo e afastando a enfermagem da assistência adequada, desde a recepção dos pacientes no centro cirúrgico até serem encaminhados a unidade de internação ou para casa. O enfermeiro como mestre da criatividade deve utilizar meios que promovam a interligação tecnologia-humanização, favorecendo a preservação do calor humano nas relações enfermeiro-paciente.

Sendo o centro cirúrgico uma unidade de alta complexidade, tecnologia e procedimentos que invadem a privacidade dos pacientes se faz necessário que os enfermeiros que ali trabalham estejam conscientizados da importância de ouvir, olhar, tocar e serem presentes, pois, a segurança e a tranqüilidade favorecem o tratamento e a recuperação. Trabalhos multidisciplinares com a equipe de enfermagem podem favorecer a sensibilização para iniciar um processo de humanização interna que tenha conseqüências no atendimento.

Desta forma, o presente estudo ressalta a importância de mudanças frente aos profissionais, por levantar questionamentos a respeito da necessidade de inovação dos conceitos sobre assistência cirúrgica e implantar uma assistência cirúrgica humanizada, deixando de buscar as características relacionadas a problemas burocráticos, estruturais e técnicos, mas sim a uma questão que envolva atitudes, comportamentos, valores e ética moral e profissional.

\section{REFERÊNCIAS BIBLIOGRÁFICAS}


ANTONIO, P.S.; MUNARI, D.B.; COSTA, H.K. Fatores geradoras de sentimentos do paciente internado frente ao cancelamento de cirurgias. Rev. Eletrônica de Enfermagem (on-line), v.04 n. ${ }^{\circ} 01$ p. 33-39, 2002. Disponível http://www.fen.ufg.br/revista/revista4 1/fatores.html.

Acesso em 01 de feveireiro de 2002.

AZEVEDO, R.C de S. A comunicação como instrumento do processo de cuidar. Visão do aluno de graduação. Rev. Nursing. n. ${ }^{\circ}$ 45, p. $19-232002$.

CAPRARA, A.; FRANCO, A. L. e S. A relação paciente-médico: para uma humanização da prática médica. Cadernos de Saúde Pública. v. 15, n. ${ }^{\circ} 03$, p. $647-654,1999$.

CARRARO, T.E. Tecnologia e humanização: da sua união as possibilidades de prevenção de infecções. Florianópolis. Rev. Texto e Contexto Enfermagem, v. 09, n. ${ }^{\circ} 01$, p 42-62, 2000.

CARVALHO, D. V.; LIMA, E. D. R. de P. Sintomas físicos de estresse na equipe de enfermagem de um centro cirúrgico. Rev. Nursing, n. ${ }^{\circ} 34$, p. 31-34, 2001.

COFEN - CONSELHO FEDERAL DE ENFERMAGEM. COREN/GO. Código de Ética dos profissionais de Enfermagem.Brasília (DF) 2000.

CRUZ, E.A da; VARELA, Z.M de V. Admissão em centro cirúrgico como espaço de cuidado. Rev. Eletrônica de Enfermagem (on-line), v 04, n. ${ }^{\circ} 01$, p. 5158, 2002. Disponível em http://www.fen.ufg.br/revista/revista4 1/centro.html.

Acesso em 01 de feveireiro de 2002.

DECLARAÇÃO UNIVERSAL DOS DIREITOS HUMANOS - OMS. Disponível em: http://www.boes.org/un/porhr-b.html. Acesso em 28/03/2003.

FIGUEIREDO, N. M. A. de. Ensinando a cuidar de clientes em situações clínicas e cirúrgicas. São Paulo. Ed. Difusão Paulista de Enfermagem. 2002.

GUEDES, M.V.C.; FELIX, V de C. S.; SILVA, L de F. da. $O$ trabalho no centro cirúrgico: representações sociais de enfermeiros. São Paulo. Rev. Nursing, n. ${ }^{\circ}$ 34, p. 20-24, 2001.

GUIDO, L. de A. Aspectos éticos da assistência de enfermagem ao cliente cirúrgico ambulatorial no centro cirúrgico e na sala de recuperação anestésica reflexões. In: Congresso Brasileiro de Enfermagem em Centro Cirúrgico, 2, São Paulo, Julho 1995. Anais. São Paulo, p. 103-107, 1995.

JOUCLAS, V. M. G.; TENCANTTI, G. T.; OLIVEIRA, V. $M$. Qualidade do cuidado de enfermagem transoperatório e de recuperação anestésica de acordo com a satisfação do cliente. Curitiba. Rev. Cogitare de Enfermagem, v. 03, n. ${ }^{\circ} 01$, p. $43-49,1998$.

LOPES, C.L. R, e cols. A comunicação profissional de saúde $\mathrm{x}$ cliente diante das novas tecnologias. Brasília. Rev. Brasileira de Enfermagem, v 51, n. ${ }^{\circ} 01$, p. 53-62, 1998.

MEEKER, M. H.; ROTHROCK, J. C. Cuidados de enfermagem ao paciente cirúrgico. Rio de Janeiro. Ed. Guanabara Koogan, $10^{\mathrm{a}}$ ed. 1997.

MENDES, I. A. C.; TREVISAN, M. A.; HAYASHIDA, M.; NOGUEIRA, M. S. Enfermagem, vínculos humanos e direitos do paciente. In: MENDES, I. A. C.;CAMPOS, E. Comunicação como meio de promover a saúde, $7^{\circ}$ Simpósio de Comunicação em Enfermagem. Anais. FIERP, Ribeirão Preto, p. 215-218, 2000.

OLIVEIRA, M. E. Mais uma nota para a melodia da humanização. In: OLIVEIRA, M. E.; ZAMPIERI, M. F. $\mathrm{M}$; BRUGGEMANN, O . M. A melodia da humanização: reflexos sobre o cuidado durante o processo do nascimento. Florianópolis. Ed. Cidade Futura, 2001.

OLIVEIRA, M.E.; BRUGGEMANN, O.M; ZAMPIERI, M. de F.M. Humanização e trabalho: razão e sentido na enfermagem. In.:ABEN.. 63 SEMANA BRASILEIRA DE ENFERMAGEM, Brasília, 2003. Caderno de dicas. Brasília, ABEn Nacional, 2002.

PUPULIM, J.S.L; SAWADA, N.O. O cuidado de enfermagem e a invasão da privacidade do doente: uma questão ético moral. Rev. Latino Americana de Enfermagem. V. 10, n. ${ }^{\circ}$ 03, p. 433- 438, 2002.

RIBEIRO, R. $\quad$ de N.;CARANDINA,D.G.D.;FUGITA,R.M.T. Tecnologia e humanização em C.C e U.T.I. São Paulo, Rev. SOBECC, v.04, n³, p.15-19, 1999.

RODRIGUES, A. L. Sensibilizando a humanizando o cuidado. Monografia de especialização apresentada a UFP-PR. Curitiba, p. 22. 2000.

RODRIGUES, M. M. M. Tecnologia e humanismo. Campinas. Rev. Reflexão, n. ${ }^{\circ} 74$, p. 59-66, 1999.

SANTOS, A.L.G.S.; BACKES, V.M.S.; VASCONCELOS, M.A. A assistência humanizada ao cliente no centro cirúrgico: uma experiência apoiada na teoria humanística de Paterson \& Zdera. São Paulo. Rev. Nursing, n. ${ }^{\circ}$ 48, p. 25-30, 2002.

SÃO PAULO, Secretaria de Estado de Saúde. Controle Social do SUS, direitos do Paciente. In.: Cartilha dos Direitos do Paciente, São Paulo, 1999[on line] disponível em: http://www.saude.sp.gov.br/csocial/html/paciente.htm Acesso em: 28/03/2003]

SILVA, L. de F. da; DAMASCENO, M.M.L; CARVALHO, C.M de L; SOUZA, P. D.S de. Cuidado de enfermagem: o sentido para enfermeiros $e$ pacientes. Brasília. Rev. Brasileira de Enfermagem, v. 54 n. ${ }^{\circ}$ 04, p. 578-588, out./dez., 2001.

TANJI S; NOVAKOSKI L. E. R. O cuidado humanístico num contexto hospitalar. Florianópolis, Rev. Texto Contexto Enfermagem, v.09, n. ${ }^{\circ}$ 02, p. 800-811, 2000.

TEIXEIRA, M.E.M.; BARBOSA, M.A; SILVA, L.F. da. Percepções dos pacientes quanto aos procedimentos invasivos no pós-operatório de cirurgias de grande porte. Brasília. Rev. Brasileira de Enfermagem, v47, n. ${ }^{\circ} 03$, p. 250-257, 1994.

VALE, E.G.; AMORIM, M.F.; FREITAS, C.B.; MELO, F.P. Orientação pré-operatória: análise compreensiva sob a ótica do cliente. Brasília. Rev. Brasileira de Enfermagem, v. 50, n. ${ }^{\circ} 01$, p. 31-36, jan./mar.1997.

VILA, V. da S. C.; ROSSI, L. A. O significado cultural do cuidado humanizado em unidade de terapia intensiva: "muito falado e pouco vivido". Rev. Latino americana de Enfermagem. v. 10, n. ${ }^{\circ} 02$, p. 137 - 144, 2002. 
WALDOW, V. R. Cuidado Humano: o resgate necessário. Porto Alegre. Ed. Sagra Luzzatto, 204 p. 1998.

Cuidado: uma revisão teórica. Porto Alegre. Rev. Gaúcha de Enfermagem, v. 13, n. ${ }^{\circ} 02$, p. 29-35, 1992.

ZAGO, M.M.F.; CASAGRANDE, L.D.R. Algumas características do processo educativo do enfermeiro cirúrgico com pacientes: um ensaio. São Paulo. Acta Paulista de Enfermagem._v. 09, n. ${ }^{\circ}$ 03, p. 52-59, 1996.

ZEN, O. P; BRUTSHER, S. M. Humanização: enfermeira de centro cirúrgico e o paciente de cirurgia. São Paulo, Rev. Enfoque; v. 14, n. ${ }^{\circ}$ 01, p. 4-6, 1986.

Texto original recebido em 17/05/2004 Aprovado para publicação em 10/12/2004 